\title{
The frequency of fall and risk factors in elderly patients with type 2 diabetes
}

\author{
Fulden Sarac ${ }^{1}$, Sumru Savas ${ }^{1}$, P. Tutuncuoglu², Asli Kilavuz ${ }^{3}$, Fehmi Akcicek ${ }^{1}$
}

\author{
${ }^{1}$ Department of Geriatrics Medicine, Ege University Medical Faculty \\ ${ }^{2}$ Department of Endocrinology and Metabolism, Atatürk Training and Research Hospital \\ ${ }^{3}$ Department of Internal Medicine, Ege University Medical Faculty \\ /Izmir/ TURKEY
}

\section{Introduction}

Falls are a leading cause of unintentional injury among adults, especially those over 65 years of age. Falls and fall-related injuries among older people are major issues for health and social care providers the world, because of the rapid increases in life expectancy observed during the twentieth century . Falls are the most serious and frequent home accident among older people. They are a major reason for admission to hospital or a residential care setting, even when no serious injury has occurred. Fall-induced injuries are increasing more rapidly than can be accounted for by the increase in the elderly population

An increased risk of serious injury due to a fall was reported among diabetic adults.

The aims of the study were to determine the frequency of falls in elderly patients with type 2 diabetes mellitus. and to evaluate the risk factors for falls.

\section{Subjects and Method}

In the study, 100 (mean age $64.9 \pm 11.0$ years)

(65 female, 35 male) elderly patients with tye $2 \mathrm{DM}$ were enroled.

Medical record abstraction of sociodemographic, clinical, and laboratory data was performed, retropectively. Medication characteristics, comorbidite, location and height of fall, associated injuries, and outcomes were obtained from patients history. with questionnaire-based interview.

A fall was described to patients as "landing on the floor or ground, or falling and hitting an object slike a table or stair."

\section{Results}

The frequency of falls found to be $21 \%$ ( 16 women, 5 men) in elderly diabetic patients, particularly in women. Mean duration of diabetes was $18.7 \pm 3.1$ years in elderly who had fall.

In this group, neuropathy and retinopathy and nephropathy and stroke and coronary heart disease and arthritis and difficulty with instrumental activities of daily living and lowgrip strength and low walking speed were found to be in 20 patients and 18 patients and 5 patients and 7 patients and 5 patients and 9 patients and 4 patients and 5 patients, respectively.

And also, 11patients reported using triple oral antidiabetic drug (OAD), 3 patients reported using OAD and insulin, 7 patients reported using only insulin. Sedative treatment was seen in 11 patients.

Mean duration of diabetes was $7.9 \pm 5.1$ years in elderly patients who had no fall. Non-ground level falls (NonGLF) were recorded in 6 patients (4 women, 2 men) $(6 \%)$. Significantly higher injuries such as hip fracture were found in 2 patients.

Mean levels of, fasting glucose, postprandial glucose and hemoglobin A1C (HbA1c) were fond to be $200.1 \pm 61.0$ $\mathrm{mg} / \mathrm{dl}, 210.9 \pm 43.9 \mathrm{mg} / \mathrm{dl}$ and $11.1 \pm 0.1$, respectively, in elderly patients who had fall.

\section{Conclusion}

Falls are significant health problem among the diabetic elderly.

Non-GLF account for $6 \%$ of patients and are associated with cronic diabetic complications, comorbide, medications, difficulty with instrumental activities of daily living and low grip strength and low walking. 